\section{Monolayer-Protected Cluster Molecules}

\author{
ALLEN C. TEMPLETON, \\ W. PETER WUELFING, AND \\ ROYCE W. MURRAY* \\ Kenan Laboratories of Chemistry, University of North \\ Carolina, Chape Hill, North Carolina 27599-3290
}

Received J une 11, 1999

\section{ABSTRACT}

In this report, we evaluate the present state of the rapidly emerging field of monolayer-protected cluster (MPC) molecules with regard to their synthesis and monolayer functionalization, their core and monolayer structure, their composition, and their properties. Finally, we canvass some of the important remaining research opportunities involving MPCs.

\section{Introduction}

Ligand-capped gold clusters have been known for a number of years; ${ }^{1}$ however, the practical formation of stable, isolable monolayer-protected clusters ${ }^{2}$ (MPCs) has only recently been demonstrated. In a seminal contribution, ${ }^{2}$ Schiffrin and co-workers showed that the classical two-phase colloid preparation of Faraday ${ }^{1 b}$ could be combined with contemporary phase transfer and alkanethiolate/ Au chemistry to prepare, in a simple procedure, very small clusters of gold atoms ( $\leq 5 \mathrm{~nm}$ average core diameter) coated with alkanethiolate monolayers.

Alkanethiolate M PCs differ from conventional colloids ${ }^{1 b}$ and nanoparticles prepared by other routes (micelle ${ }^{3 a}$ and polymer stabilization, ${ }^{3 b}$ gas-phase cluster formation, ${ }^{3 c}$ stabilization with small organic ligands ${ }^{1 a, 4}$ ) in that they can be repeatedly isolated from and redissolved in common organic solvents without irreversible aggregation or decomposition. This attribute and the air stability of MPCs are difficult to overemphasize, since they allow for handling and derivatization of MPCs in ways familiar to molecular chemists, plus considerable flexibility in characterization relative to previous nanoparticle embodiments. ${ }^{5}$

Metallic and semiconducting nanoparticles represent a scantily explored materials dimension that bridges bulk

Allen C. Templeton was born in Paris, Texas, in 1972 and is a graduate of Texas A\&M University at Commerce (B.S., 1994). After two years at Texas Instruments (1994-1996), he entered the Ph.D. program at UNC and is currently a fourthyear graduate student working in Professor Murray's laboratory.

W. Peter Wuelfing was born in Freehold, New J ersey, in 1974 and is a graduate of the University of North Carolina (B.S., 1996). He is currently a fourth-year graduate student in the Ph.D. program at UNC working in Professor Murray's laboratory.

Royce W. M urray was educated at Birmingham Southern College (B.S., 1957) and Northwestern University (Ph.D., analytical chemistry, 1960), and joined the UNC faculty in 1960. Murray has published over 330 papers on electrochemical methodology and interfaces. He is a member of the National Academy of Sciences and is Editor of the ACS journal Analytical Chemistry. material and molecular behavior ${ }^{6}$ and offers prospects of novel, and even size-dependent, chemical, electronic, and physical properties. Such properties may, additionally, depend on whether nanoparticles comprise organized monolayer or multilayer films or are solutions of organized or randomly dispersed entities. Following a long-standing interest in nanometer-scale materials, ${ }^{7}$ we adopted Schiffrin's procedure ${ }^{2}$ in an exploration of the synthesis, characterization, and functionalization of MPCs as a new molecular class. Also of interest are structural analogies of MPCs to self-assembled monolayers on flat surfaces ${ }^{8}$ (2D-SAMs) and to large, spatially defined macromolecules, such as dendrimers. ${ }^{9}$ Progress in these directions by our laboratory and other laboratories forms the core of this Account. ${ }^{10}$

\section{MPC Synthesis}

In the original Schiffrin reaction, ${ }^{2}$ addition of dodecanethiol to organic-phase $\mathrm{AuCl}_{4}^{-}$(1:1 mole:mole), followed by reduction with $\mathrm{BH}_{4}^{-}$, leads to dodecanethiolateprotected Au clusters having a $1-3 \mathrm{~nm}$ range of core diameters:

$$
\begin{gathered}
\mathrm{AuCl}_{4}^{-} \text {(toluene) }+\mathrm{RSH} \rightarrow\left(-\mathrm{Au}^{\prime} \mathrm{SR}-\right)_{\mathrm{n}} \text { (polymer) } \\
\left(-\mathrm{Au}^{\prime} \mathrm{SR}-\right)_{\mathrm{n}}+\mathrm{BH}_{4}^{-} \rightarrow \mathrm{Au}_{\mathrm{x}}(\mathrm{SR})_{\mathrm{y}}
\end{gathered}
$$

Subsequent reports have shown that a wide range of al kanethiolate chainlengths (C3-C24), 5,11 $\omega$-functionalized al kanethiolates, ${ }^{12}$ and dialkyl disulfides ${ }^{13}$ can be employed in this same protocol (Scheme 1). An example MPC formula is $\mathrm{Au}_{145}\left(\mathrm{~S}_{(}\left(\mathrm{CH}_{2}\right)_{5} \mathrm{CH}_{3}\right)_{50}$.

The details of reactions 1 and 2 have not been completely dissected; however, the reaction's behavior is consistent with a nucleation-growth-passivation process: (i) Larger thiol:gold mole ratios give smaller average MPC core sizes, 5,14 and (ii) fast reductant addition and cooled solutions produce smaller, more monodisperse MPCs. ${ }^{5,15 a}$ (iii) Quenching the reaction immediately following reduction produces higher abundances of very small core sizes $(\leq 2 \mathrm{~nm}) .15 \mathrm{~b}, \mathrm{c}$

The Schiffrin reaction tolerates considerable modification in regard to the protecting ligand structures (Scheme 1). ${ }^{16}$ While alkanethiolate MPCs (a) are nonpolar, highly polar ligands $(b-d)$ can yield ${ }^{16 a-c}$ water-soluble MPCs in modified syntheses. MPCs with arenethiolate ${ }^{16 \mathrm{~d}-\mathrm{g}}(\mathrm{e}-\mathrm{g})$ and ( $\gamma$-mercaptopropyl)trimethyloxysilane ligands (h) have also been prepared. ${ }^{16 h}$ Sterically bulky ligands (larger footprint) tend to produce smaller Au core sizes (relative to alkanethiolate MPCs prepared using equal thiol/ $\mathrm{AuCl}_{4}-$ ratios), suggesting ${ }^{16 b, c, e}$ a steric connection (as yet unproven) to the dynamics of core passivation.

The core metal of MPCs can also be varied, and reports of MPCs with $\mathrm{Ag}{ }^{17 a, b}$ and alloy ( $\mathrm{Au} / \mathrm{Ag}, \mathrm{Au} / \mathrm{Cu}, \mathrm{Au} / \mathrm{Ag} / \mathrm{Cu}$, $\mathrm{Au} / \mathrm{Pt}, \mathrm{Au} / \mathrm{Pd}$, and $\mathrm{Au} / \mathrm{Ag} / \mathrm{Cu} / \mathrm{Pd}$ ) cores (monolayerprotected alloy clusters, MPACs) ${ }^{17 b}$ have appeared. Ag MPCs and MPACs, like their MPC counterparts, are 
Scheme 1. Examples of Thiol Ligands Used To Prepare MPCs ${ }^{a}$

(a) $\mathrm{HS}-\left(\mathrm{CH}_{2}\right)_{\mathrm{n}}-\mathrm{CH}_{3}(\mathrm{n}=3-23)$

(b) $\mathrm{HS}$<smiles>NC(CCC(=O)NC(CS)C(=O)NCC(=O)O)C(=O)O</smiles>

(c)<smiles>CC(S)C(=O)NCC(=O)O</smiles>

(d) $\mathrm{HS}-\left(\mathrm{CH}_{2}-\mathrm{CH}_{2}-\mathrm{O}\right)_{n}-\mathrm{CH}_{3} \quad(\mathrm{n}=7$ or 112$)$<smiles>Oc1ccc([Hg])cc1</smiles>

(f) $\mathrm{H}$<smiles>CCCCCCCCCCCCCCCCCCCCOc1ccc(OCCCC[Si])cc1</smiles>

(g) $\mathrm{HS}-\left(\mathrm{CH}_{2}\right)_{\mathrm{n}} \longrightarrow(\mathrm{n}=2$ or 4$)$

(h) $\mathrm{HS}^{-} \overbrace{\mathrm{CH}_{3} \mathrm{O}^{\prime}} \mathrm{Si}^{\mathrm{OCH}_{3}}$

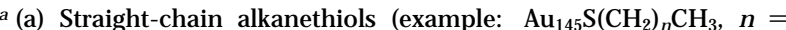
2-23), ${ }^{5,11}$ (b) glutathione (example: $\mathrm{Au}_{28} \mathrm{Glutathione}{ }_{16}$ ), ${ }^{16 a}$ (c) tiopronin (example: $\mathrm{Au}_{201}$TTiopronin$_{85}$, ,6b (d) thiolated poly(ethylene glycol) (example: $\mathrm{Au}_{807} \mathrm{PEG}_{98}$ ), ${ }^{16 c}$ (e) p-mercaptophenol, ${ }^{169}$ (f) aromatic alkane thiol, $16 \mathrm{f}(\mathrm{g})$ phenyl alkanethiols (example: $\left.\mathrm{Au}_{314} \mathrm{PhC} 4 \mathrm{~S}_{143}\right),{ }^{16 \mathrm{e}}$ and $(\mathrm{h})(\gamma$ mercaptopropyl)-trimethoxysilane. ${ }^{16 \mathrm{~h}}$

generally air- and solvent-stable and obtained in high yield. The core metals in MPACs appear to be partly radially segregated, and some exhibit enhanced stability relative to their mono-metal counterparts. ${ }^{17 b}$

\section{Characterization of MPCs}

The excellent handling properties of MPCs facilitate their structural and compositional analysis, which can be divided into analytical information about the central core and the surrounding monolayer.

Core Size and Shape. The core dimensions of MPCs have been measured-with generally good agreementby scanning tunneling microscopy (STM), ${ }^{11}$ atomic force microscopy (AFM), ${ }^{11}$ transmission electron microscopy (TEM), 2,5,15a small-angle X-ray scattering (SAXS), ${ }^{5,11}$ laser desorption-ionization mass spectrometry (LDI-MS), ${ }^{15}$ and X-ray diffraction (XRD).5,14 TEM allows concomitant observation of the self-ordering and regular core-core spacing found ${ }^{18}$ in thin MPC films.

Knowing and controlling the dispersity of core size is also important. Figure 1 illustrates the use ${ }^{15 a}$ of LDI-MS to track the solubility-fractionation of dodecanethioate MPC core sizes, conducted in concert with theoretical modeling to predict the core size and shape of isolated fractions. The number of atoms per core tends toward closed shell structures ("magic numbers") with an equilibrium truncated octahedral shape. As a cautionary note, however, reactions 1 and 2 are based on competing core growth/passivation kinetics, so the occurrence of non-

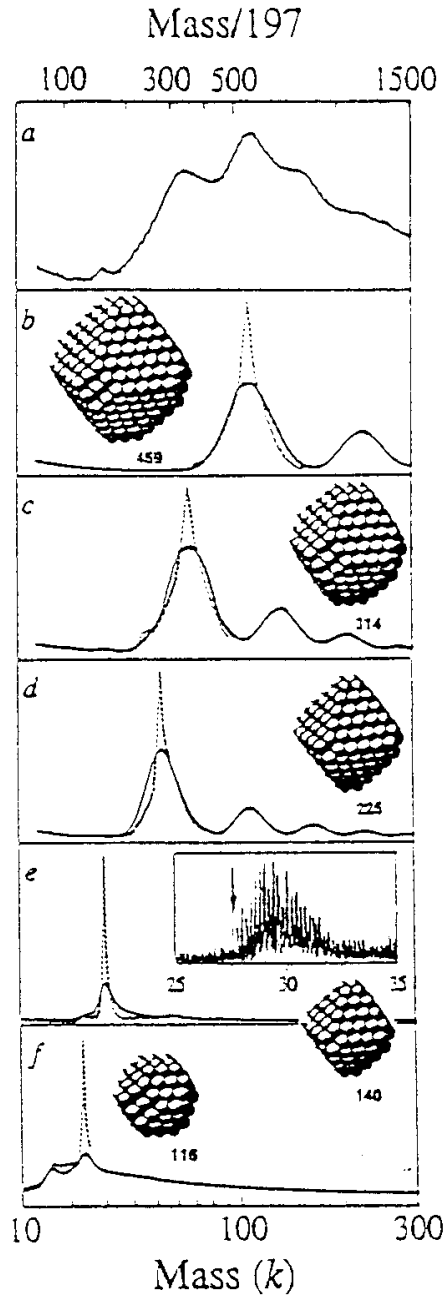

FIGURE 1. Laser desorption/ionization (LDI) mass spectra (mass in $k=10^{3} \mathrm{amu}$, and mass/197 = equivalent number of gold atoms) of (a) a crude dodecanethiolate M PC mixture, (b-e) fractionated M PCS, and (f) a mixture of the two lightest fractions. Higher mass peaks in traces $d$ and e are gas-phase, trimers, etc. Inset structures are predicted optimal core structures, and the inset in trace e is a highresolution mass spectrum plotted on a linear mass scale (arrow marks the first peak at $27609 \pm 2$ amu). Reprinted with permission from ref 15a. Copyright 1996 W iley-VCH Publishing.

equilibrium MPC shapes cannot be discounted. Analysis of water-soluble MPCs with highly polar ligands is less advanced, but dispersities have been resolved by gel ${ }^{16 a}$ and capillary electrophoresis ${ }^{16 b}$ and fractions in the former examined with MALDI-MS.

MPC Monolayers. MPC monolayer shells have also been examined with multiple techniques.5,11,19 Most studies have been conducted on polydisperse (core size) MPCs, so the data represent averages. Elemental analysis ${ }^{11}$ is consistent with intact RS- ligands (reactions 1 and 2). The average number of ligands per core is derived from a combination of $\mathrm{XPS}^{5}$ or thermogravimetric $\mathrm{C}^{5,11}$ and core size analyses. ${ }^{15 a}$ The MPC ligand coverages $-50 \%$ or more ${ }^{5}$ are larger than the 33\% (ligand/surface Au atom) coverage characteristic of 2D-SAMs on $\mathrm{Au}(111)$ terraces. Theoretical calculation $\mathrm{s}^{20}$ indicate that this high coverage results from larger ligand/Au binding ratios on core edges and vertexes (confirming our own ${ }^{5}$ modeling). Experiments addressing 


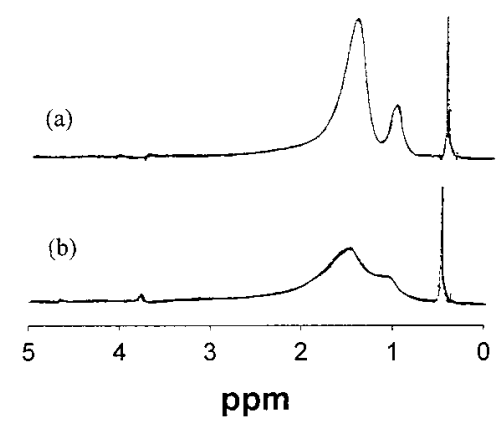

FIGURE 2. ${ }^{1} \mathrm{H}$ NMR spectra (in $\mathrm{C}_{6} \mathrm{D}_{6}$ ) of dodecanethiolate MPCS: (a) 2.0 and (b) $4.4 \mathrm{~nm}$ average core diameter. ${ }^{5}$

the nature of MPC ligands provides strong evidence, ${ }^{5,20,21}$ that, like 2D-SAMS, they should be regarded as covalentlyattached thiolate-like units, not adsorbed disulfides. Our reference to the ligand as a thiolate should not be taken as signifying an ionic $\mathrm{RS}^{-} \mathrm{Au}^{+}$moiety.

NMR spectroscopy is particularly informative about the structure and content of MPC monolayers. ${ }^{5,11,19 a-d ~}{ }^{1} \mathrm{H}$ and ${ }^{13} \mathrm{C}$ NMR resonances of MPC monolayers are characteristically broadened relative to those of free alkanethiols; the factors ${ }^{5,19 c}$ include spin-spin relaxational $\left(T_{2}\right)$ broadening, a distribution in chemical shifts due to differences in Au-SR binding sites, and a gradient in monolayer packing density from near-core to chain terminus with associated dipolar broadening. Figure 2 illustrates the broadening of ${ }^{1 H}$ NMR resonances of dodecanethiolate MPCs with increased core size, which for the methyl resonance $\left(\delta \sim 0.9\right.$ ) is thought to reflect primarily $\mathrm{T}_{2}$ broadening. The products of MPC functionalization reactions can be assessed with NMR data, generally more accurately following $\mathrm{I}_{2}$-induced MPC decomposition to a disulfide solution. ${ }^{21}$

Vibrational spectroscopy has shown ${ }^{8}$ that alkanethiolate chains of 2D-SAMs are typically in an all-trans, zigzag configuration. Chain conformations in solid-state MPC films ${ }^{19}$ while mostly all-trans, also contain significant (5$25 \%$ ) gauche defect concentrations at both inner and terminal chain ends, especially for longer chainlengths and above the chain melting temperature. Hydrogen bonding can be an important structural component in MPCs with polar monolayers. ${ }^{16 a, b}$ Monolayer ordering in solid-state MPC samples is also associated with interdigitation of chain domains (or "bundles") on neighboring cluster molecules. ${ }^{19 c, e}$ In contrast, monolayers of dissolved alkanethiolate MPCs exhibit disorder comparable to that of liquid alkanes. That MPC monolayers prove to be only rough analogies of $2 \mathrm{D}-\mathrm{SAM}$ s is likely due to the high proportion of classically defined MPC core surface defect sites (edges, vertexes). ${ }^{21}$

Order-disorder transitions in solid-state alkanethiolate MPCs are detectable with differential scanning calorimetry (DSC) and variable-temperature IR and NMR spectroscopies (Figure 3). ${ }^{19 a-c}$ The transition temperatures increase with methylene chain length (like melting of crystalline alkane hydrocarbons) and, by FTIR, are accompanied by increased gauche defect concentrations. ${ }^{19 a}$ Transition enthalpies (scaled to the organic fraction of the
MPC) also increase with methylene chainlength, and are smaller than those of corresponding alkanes. ${ }^{19 c}$

In an elegant order-disorder study, Lennox and coworkers ${ }^{19 c}$ applied variable-temperature solid-state ${ }^{2} \mathrm{H}$ NMR to MPCs with deuterated octadecanethiolate monolayers. The results showed that, as temperature is increased, disorder (increase in gauche bond population) propagates from the chain terminus toward the middle of the chain, leading to eventual chain melting, but does not extend to the tethered sulfur headgroup.

\section{Reactivity of MPCs}

Understanding reactivities of MPC monolayers and developing efficient strategies to functionalize them is key to their application in areas such as catalysis and chemical sensing. Toward this end, we have investigated ligand place-exchanges (to form poly-homo- and -hetero-functionalized MPCs), ${ }^{22}$ nucleophilic substitutions, ${ }^{21}$ and ester and amide couplings (Scheme 2). ${ }^{23}$ The resulting MPCs are large molecules with multiple functionalities, spherically organized around a central, metal core, a spatial arrangement suggesting analogy to dendrimers. ${ }^{9}$ However, whereas dendrimers are typically more dense at their perimeter than core, MPCs are "soft objects with hard cores".

Place-Exchange Reactions. Ligand place-exchange was a key step $22 a$ in opening up MPC functionalization. For example, MPCs with alkanethiolate monolayers (RS) can be functionalized with R'S groups by the reaction (Scheme 2a)

$$
x\left(R^{\prime} S H\right)+(R S)_{m} M P C \rightarrow x(R S H)+\left(R^{\prime} S\right)_{x}(R S)_{m-x} M P C
$$

where $x$ and $m$ are the numbers of new and original ligands, respectively.22a The rate and equilibrium stoichiometry $(x)$ of reaction 3 are controlled by factors that include the (reaction feed) mole ratio of R'SH to RS units, their relative steric bulk, and $R$ versus $R^{\prime}$ chainlengths. ${ }^{22 b}$

Study ${ }^{22 c}$ of ligand place-exchange dynamics and mechanism shows that exchange (i) has a 1:1 stoichiometry, (ii) is an associative (as opposed to dissociative) reaction, (iii) yields the displaced ligand in solution as a thiol, and (iv) does not involve disulfides or oxidized sulfur species. The time-dependent rate of place-exchange was interpreted as reflecting a hierarchy of different core surface binding sites with associated susceptibility (vertexes, edges $\gg$ terraces) to place-exchange.

Reactivity of $\omega$-Functional Groups. Functional groups on the outermost portion of the MPC ligand sphere can straightforwardly undergo many synthetic transformations. In an early example, ${ }^{16 g, 24}$ Schiffrin reported the esterification of p-mercaptophenol-protected MPCs using propionic anhydride (Scheme 2b).

Our laboratory examined ${ }^{21}$ steric effects in MPC reactivity with $\mathrm{S}_{\mathrm{N}} 2$ reactions of mixed monolayer MPCs containing $\omega$-bromoalkanethiolates (Scheme 2c). The reactivities are similar to those of primary alkyl halide monomers $(\mathrm{RBr}),{ }^{21}$ a result sharply divergent from re- 


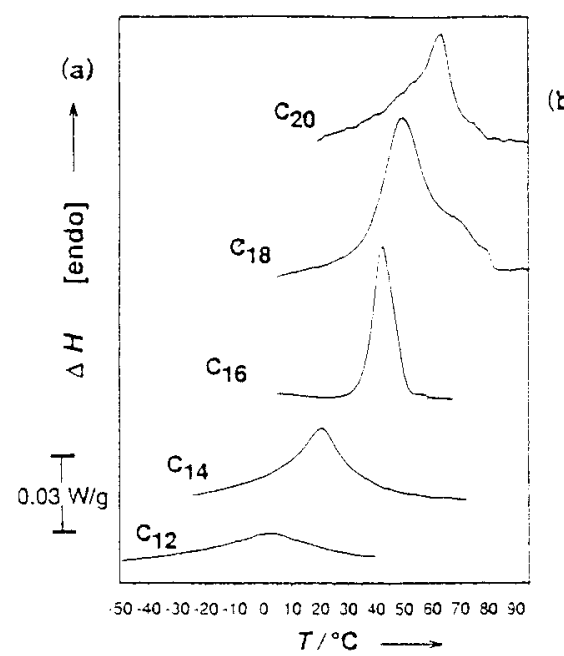

(b)
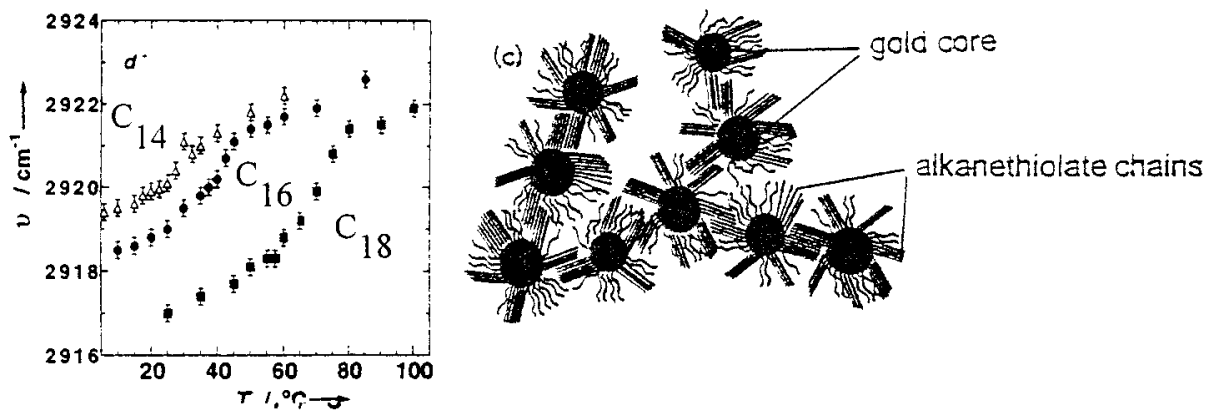

FIGURE 3. Phase transitions in MPC alkanethiolate monolayers. ${ }^{19}$ (a) Differential scanning calorimetry of alkanethiolate MPCs. (b) Peak energy, from FTIR spectroscopy, as a function of temperature for the antisymmetric $\left(\mathrm{d}^{-}\right)$methylene stretching vibrations of alkanethiolate MPCs. Higher energy values are diagnostic of chain disorder. (c) Cartoon of chain bundle intercalation.

ports $^{25}$ of analogous reactions on 2D-SAMs. The $\mathrm{S}_{\mathrm{N}} 2$ reactivity did slow with increasing steric bulk of primary amine nucleophiles, but even $\omega$-bromo sites "buried" in the monolayer were reactive (albeit more slowly than "exposed" ones). These results reflect a monolayer disorder consistent with the results of vibrational spectroscopy of dissolved MPCs. ${ }^{19}$

Amide and ester coupling reactions give access ${ }^{23}$ to alkanethiolate/ Au-based MPCs bearing multiple copies of a very diverse selection of structural groups. The reactions start from a small and readily prepared (by placeexchange) subset of $\omega$-functionalized MPC materials (Scheme 2d). Attractive features of this synthetic strategy are the following: (i) the available amide and ester activating agents are diverse, (ii) a plethora of target molecules with amine, carboxylic acid, or alcohol substituents is available, and (iii) the synthesis (often not facile) of $\omega$-functionalized alkanethiol derivatives, required in the place-exchange pathway, is avoided. The coupling strategy has been extended to functionalize water-soluble MPCs $^{26}$ and to CdS nanoparticles. ${ }^{27}$

Other MPC functionalization strategies include coupling of MPCs with functionalized silane monolayers with mercaptosilane monomers (Scheme 2e), ${ }^{\text {6h }}$ forming cagelike structures surrounding the gold core. Mirkin's group has used $\omega$-norbornenyl-functionalized MPCs to grow polymeric shells from a M PC surface using a functionalgroup-tolerant ruthenium carbene ROMP catalyst (Scheme 2f); ${ }^{28}$ these shells can be functionalized with virtually any norbornenyl-containing monomer.

\section{Chemical Properties of Functionalized MPCs}

MPCs bearing spectroscopic (fluorophores and chromophores) and redox groups (Figure 4) have been prepared using the above reactions.

Electrochemistry. Electrode reactions of poly-redoxfunctionalized clusters are unusual in that many equivalents of redox charge per MPC can be delivered, under diffusion control, to the electrode/ solution interface. The few known precedents of poly-electron transfer reactions include soluble redox polymers ${ }^{29}$ and redox-labeled dendrimers. ${ }^{9}$ MPCs have been poly-functionalized with ferrocene ( $\leq 25$ sites per MPC), 22a,30 anthraquinone $(\leq 25),{ }^{31}$ phenothiazine $(\leq 7),{ }^{23}$ and viologen $(\leq 36)^{26}$ groupings. Figure 4a illustrates voltammetry ${ }^{30 a}$ of a $\mathrm{FC}_{9}-\mathrm{MPC}$ solution; analogous ferrocenes have been examined as Langmuir monolayers at the air/water interface. ${ }^{30 \mathrm{c}}$ MPCs that are poly-hetero-functionalized ${ }^{22 b}$ with mixtures of ferrocene and anthraquinone sites exhibit voltammetry of the two groups, occurring independently of each other. Diffusion coefficients from electrochemical measurements have been compared with those from Taylor dispersion experiments. ${ }^{32}$

The poly-electron transfer reactions studied so far 22,30,32 are mass transport-controlled one-electron events that rapidly occur either serially or independently parallel. All attached groups are electroactive..$^{23}$ The electrochemical observations also include currents for charging of the electrical double layers of the MPC Au cores, a characteristic reflecting equivalence of MPCs to "diffusing nanoelectrodes".

Multiple MPC electron donor and acceptor groups invite applications to mediated electrocatalysis. The basic prospects include concerted poly-electron exchanges with substrates, intramolecular electron transfer reactions during binding of MPCs to substrates (perhaps transiently), and ("cofactor") M PCs that are "multipurpose" by allowing both electron and proton transfers with a substrate in electron-proton coupled reactions. When the polyredox groups are weakly electronically coupled to the Au core, mediated electrocatalysis is likely to occur only by sequential one-electron transfers. A significant step toward truly concerted poly-electron transfers will be shortening (or altogether removing) the connecting spacers between the redox groups and the metal-like $\mathrm{Au}$, so as to promote strong electron donor-acceptor/core electronic coupling.

Our first ${ }^{31}$ probe of mediated electrocatalysis with MPCs was based on the reduction of gem-dinitrocyclo- 
Scheme 2. Reactivity of Monolayer-Protected Clusters ${ }^{\text {a }}$

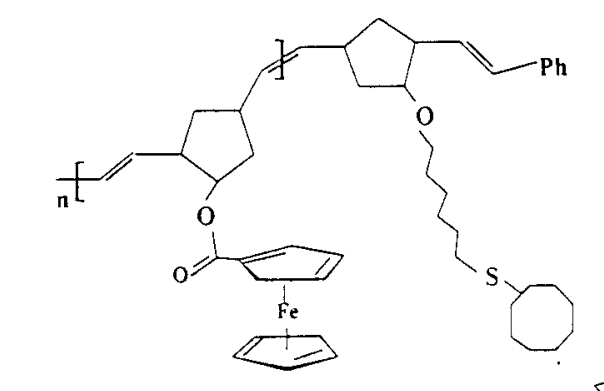

\section{Place-Exchange}

\section{Polymerizations}

(f)

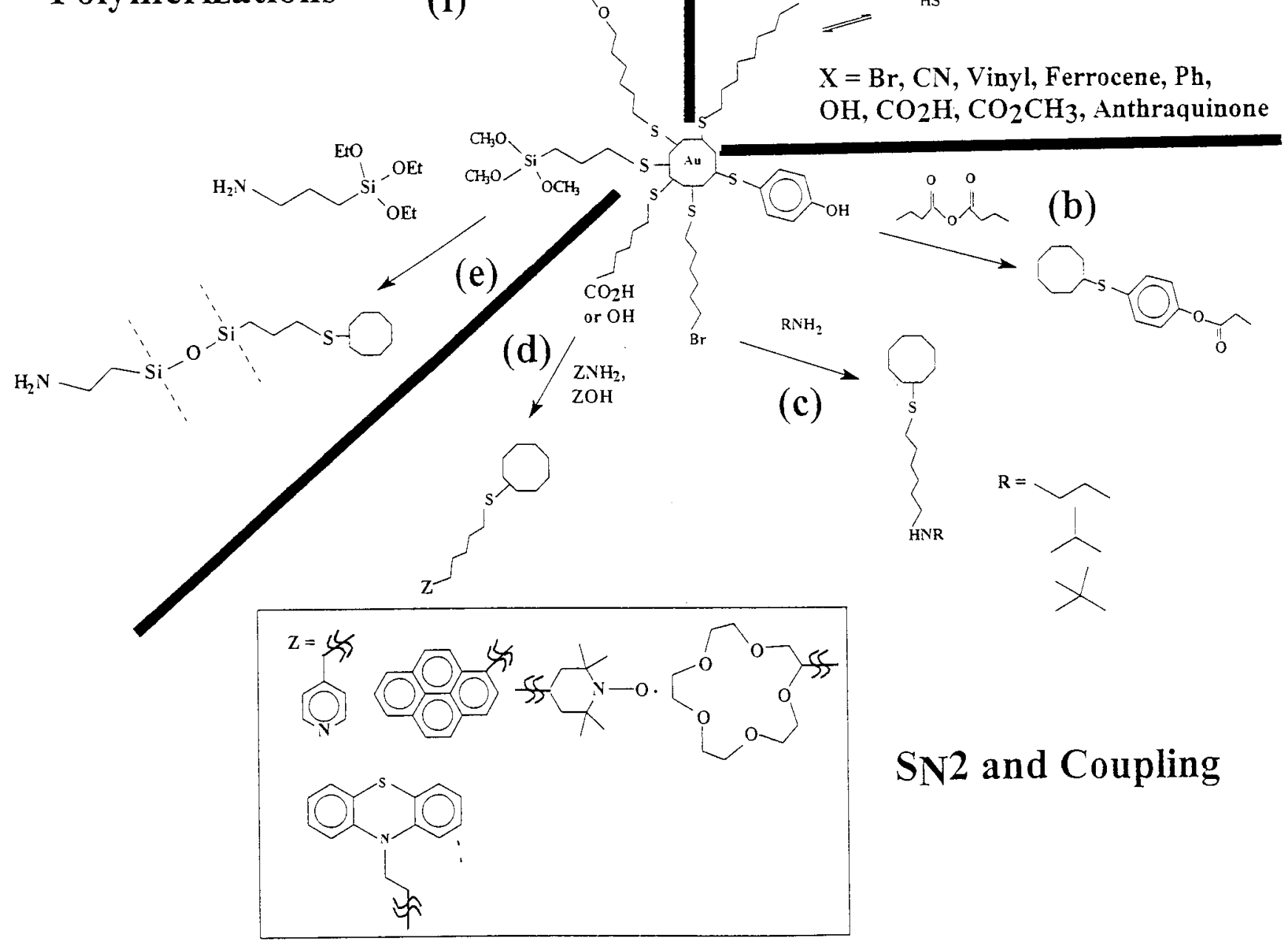

a (a) Place-exchange, 22 (b) reaction of p-mercaptophenol with propionic anhydride, ${ }^{16 g}$ (c) $\mathrm{S}_{\mathrm{N}} 2$ reaction of $\omega$-bromoalkanethiolated MPCs with primary alkylamines, ${ }^{21}(\mathrm{~d})$ amide and ester coupling reactions, ${ }^{23}$ (e) siloxane formation reactions, ${ }^{16 \mathrm{~h}}$ and (f) transition-metal-catalyzed ring-opening metathesis polymerization (ROMP). ${ }^{28}$

hexane (DNC) by clusters bearing ca. 25 electrogenerated anthraquinone radical anion $\left(\mathrm{AQ}^{-}\right)$sites. This study showed that (i) MPC and monomeric $\mathrm{AQ}^{-}$site reactivities with DNC were nearly the same, and (ii) the observed electrocatalytic currents are enhanced, relative to freely diffusing $\mathrm{AQ}^{-}$, due to the smaller diffusion coefficient of MPC AQ ${ }^{-}$and ensuing compression of the reaction layer.

Other Attached Groups. MPCs can, of course, be endowed with other forms of behavior by choice of the poly-functionality. The carboxylic acids of water-soluble tiopronin MPCs (Scheme 1) can be titrated as weak acids (Figure 4b), revealing electrolyte concentration-dependent charge repulsion affects analogous to those of polyprotic acids. ${ }^{16 b}$ Labeling MPCs with fluorophores may lead to reagents useful in chemical analysis. Tiopronin MPCs functionalized with fluorescein ${ }^{26}$ ( 3.7/MPC) showed $\sim 50 \%$ lower luminescence compared to fluorescein monomer, suggestive of energy transfer to the gold core (Figure 

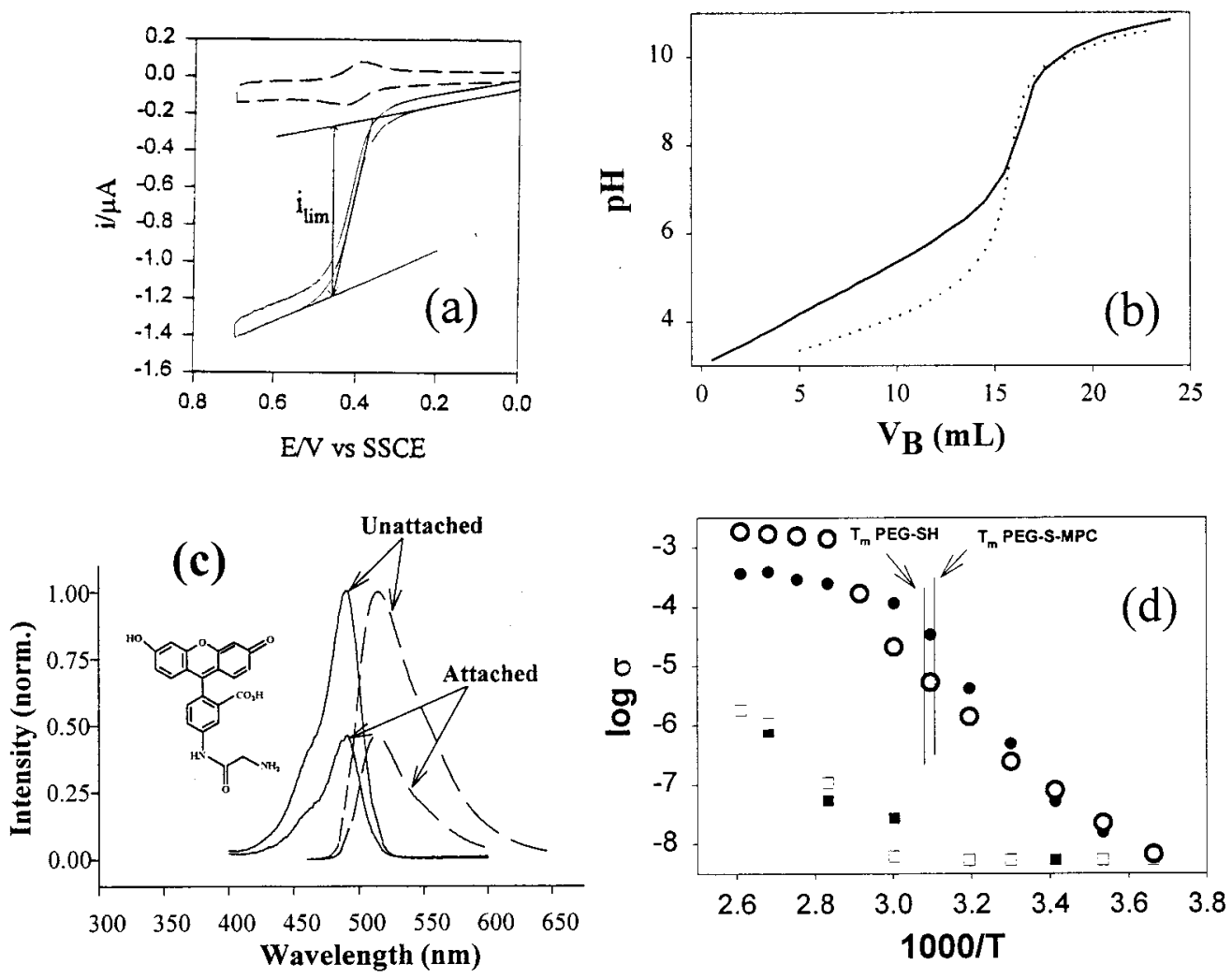

FIGURE 4. (a) Cyclic voltammograms of $\omega$-ferrocenyloctanethiolate MPC (average $9 \mathrm{Fc} / \mathrm{MPC}$ ) at $0.15 \mathrm{~cm}^{2}$ stationary (- -) and rotated (-, 1600 rpm) glassy carbon disk electrodes in dichloromethane. ${ }^{30 a}$ (b) Acid-base titration of tiopronin $\mathrm{MPC}$ with $\mathrm{NaOH}_{;} 20 \mathrm{mM} \mathrm{NaNO}{ }_{3}$ added (apparent $\left.p K_{\mathrm{A}}=4.77 \pm 0.41\right), 1 \mathrm{M} \mathrm{NaNO}_{3}$ added $\left(\cdots\right.$, apparent $\left.\mathrm{p} K_{\mathrm{a}}=3.95 \pm 0.27\right)$. ${ }^{16 \mathrm{~b}}$ (c) Excitation and emission fluorescence spectra of 0.5 $\mu \mathrm{M} \mathrm{5}$-(aminoacetamido)fluorescein monomer (upper set of curves) and $0.5 \mu \mathrm{M}$ (in fluorophore) tiopronin M PC, poly-functionalized with the monomer in buffer. ${ }^{26}$ (d) Ionic conductivity of $\mathrm{LiClO}_{4}$, at 16:1 polymeric oxygen to $\mathrm{LiClO}_{4}$, in neat thiolated poly(ethylene glycol) ( $(\mathbf{O})$ and poly(ethylene glycol) MPC (O). Ionic conductivity of neat thiolated poly(ethylene glycol) ( $\square$ ) and poly(ethylene glycol) M PC ( $\square$ ) with no added $\mathrm{LiClO}_{4}{ }^{16 \mathrm{c}}$

4c). Novel polymer electrolytes can be fashioned by using polyether MPC ligands, such as thiolated poly(ethylene glycol) (Figure 4d). This material dissolves $\mathrm{Li}^{+}$salts and, for reasons not yet understood, is more ${ }^{16 c}$ ionically conductive than the corresponding polyether ligand.

We anticipate that further studies will reveal that chemical properties such as the above are, to some extent, tunable as a function (for example) of coverage on the nanoparticle surface, of core properties (size, charge, metal), and of relative chainlengths of core-to-functional group connections.

\section{Properties of MPC Cores}

Core Spectroscopy. X-ray photoelectron spectroscopy (XPS) of 2D-SAMs shows Au 4 f binding energies very near those of $\mathrm{Au}(0)$ and $\mathrm{S} 2 \mathrm{p}$ binding energies, consistent with a $\mathrm{RS}^{-}$ligand. Like 2D-SAMs, MPCs ${ }^{2,5,11}$ give energies distinctive of $\mathrm{Au}(0)$ and a surface thiolate, indicating that the bond is somewhere between RS-M and RS- $\mathrm{M}^{+} .33$ These results are striking inasmuch as as many as about one-third of the Au atoms in the MPC bear alkanethiolate ligands. ${ }^{5}$ Only for the smallest cores is a suggestion of an increased binding energy seen.

UV-visible spectra of nanometer-sized MPCs contain $^{15,34}$ several features. The strong UV absorption of the

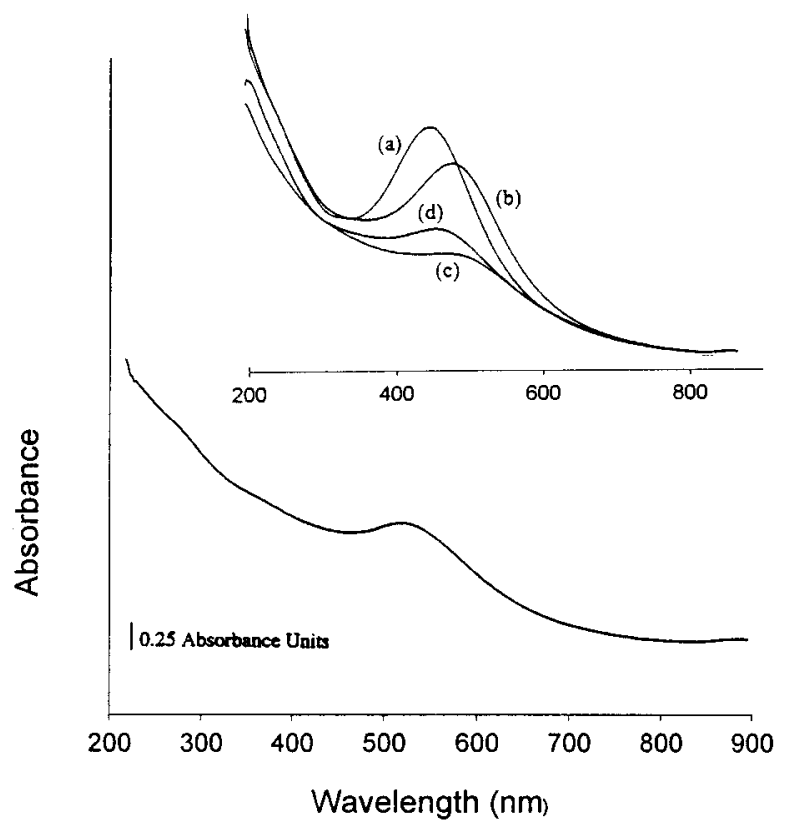

FIGURE 5. UV/vis spectrum of dodecanethiolate M PC with $3.0 \mathrm{~nm}$ average Au core diameter. ${ }^{5}$ Inset: Spectra of dodecanethiolate MPCs with alloy cores: (a) $A_{u A g} 2.5\left(\lambda_{\max }=468 \mathrm{~nm}\right)$, (b) $A u A g_{1.4}$ $(504 \mathrm{~nm}),(\mathrm{c}) \mathrm{AuAg}_{0.4}(518 \mathrm{~nm})$, (d) AuA go.9Cu $0.4(488 \mathrm{~nm}){ }^{176}$ All spectra were aquired at $\sim 10^{-6} \mathrm{M}$ concentration in hexane. 
(a)

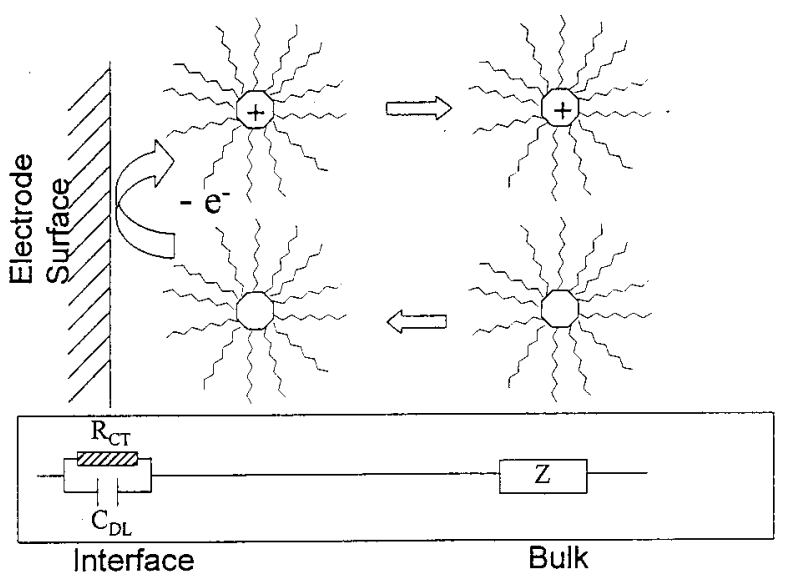

(b)

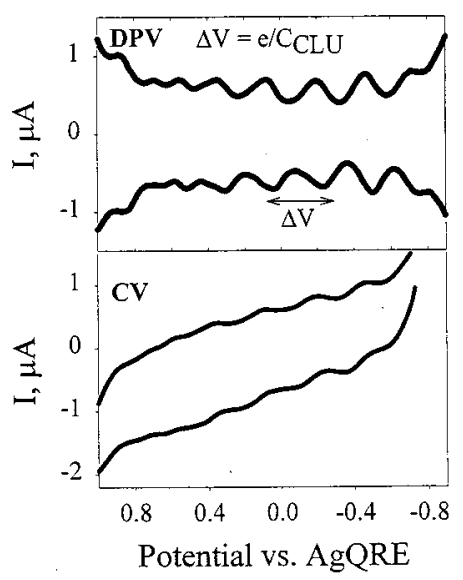

(c)

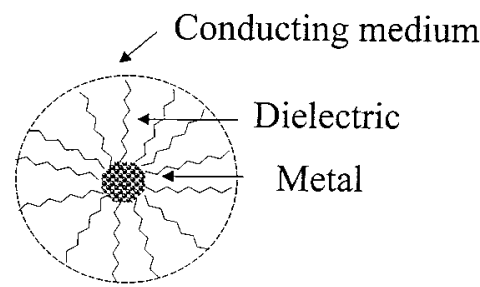

(d)

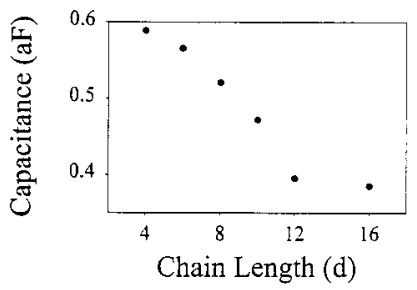

FIGURE 6. (a) Cartoon of quantized double layer (QDL) charging of neutral MPCS (with PCZ core potential) diffusing from bulk solution to an electrode/solution interface with a potential $E_{\mathrm{PZC}} \pm \mathrm{e} / \mathrm{C}_{\mathrm{CLW}}$; all M PC cores are charged to that potential by \pm a single electron. The M PCs then diffuse back into the solution. Box: Equivalent circuit, which determines current flow, in which $R_{C T}$ and $C_{D L}$ are interfacial charge transfer resistance (between electrode and M PC) and electrode double layer capacitance, respectively, and $Z$ is M PC diffusional (Warburg) impedance. (b) Cyclic voltammogram (bottom) and differential pulse voltammogram (top) of hexanethiolate $\mathrm{Au} \mathrm{M} \mathrm{PC}$, in $\mathrm{CH}_{2} \mathrm{Cl}_{2}$ at a $1.6 \mathrm{~mm}$ diameter $\mathrm{Au}$ working electrode. ${ }^{35 d}$ (c) Cartoon of the concentric sphere capacitor model used in describing M PC capacitance. (d) Average M PC capacitance versus chainlength. ${ }^{31 d}$

Au core decays roughly exponentially into the visible, with a broad surface plasmon (SP) band superimposed at 500 $\mathrm{nm}$ that decreases in intensity and energy (slightly) with decreasing core size (Figure 5). ${ }^{5}$ For monolayer-protected clusters with alloy cores, ${ }^{17 b}$ the SP band positions and intensities are, interestingly, intermediate between those of corresponding mono-metal MPCs (Figure 5 inset).

Spectra of very small, monodisperse Au MPCs (1.1$1.9 \mathrm{~nm}$ core diameter) develop distinct steplike structures, indicative of more molecule-like properties and transitions to discrete LUMOs of the conduction band. ${ }^{15 b, 34}$ Such spectra have been used to estimate HOM O-LUMO "gap" energies as a function of core size for Au MPCs. ${ }^{35 a}$

Core Charging Properties. The quantization of double layer capacitance charging is one of the more interesting solution electrochemical properties of alkanethiolate MPCs. The capacitance is associated with the ionic space charge formed around an MPC dissolved in an electrolyte solu- tion, upon electronic charging of the core. Because of the small, sub-attofarad $(\mathrm{aF})$ capacitance $\left(\mathrm{C}_{\mathrm{CLU}}\right)$ of an MPC, charging of the tiny capacitor by single electrons occurs in potential intervals, $\Delta V=\left[e / C_{C L U}\right]$, that exceed $k_{B} T .{ }^{35 a, b}$ These potential intervals are readily observable in voltammetry (Figure $6 \mathrm{~b}$ ) of MPC solutions. The discretized (one electron) double layer charging steps are smeared out when the MPC core sizes are not mono-disperse or are too large. ${ }^{35 c}$ Quantized MPC double layer charging is formally analogous to classical STM-based "Coulomb staircase" experiments on single MPCs, ${ }^{35 a, b}$ but the equivalent circuits differ. ${ }^{35 a}$ Our initial descriptor, "ensemble Coulomb staircase charging", has been replaced with the simpler and more accurate one, "quantized double layer charging".

The spacing of the current peaks on the potential axis in Figure $6 \mathrm{~b}$ reflects the underlying nature of the MPC core charging process. ${ }^{35}$ An even peak spacing signifies a 


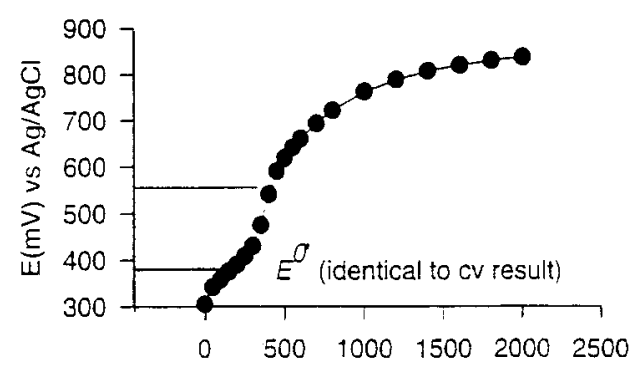

FIGURE 7. Incremental additions of a $0.30 \mathrm{mM} \mathrm{MPC}$ solution charged to $+0.92 \mathrm{~V}$ to $5 \mathrm{~mL}$ of $76 \mu \mathrm{M}$ ethylferrocene, ${ }^{36 \mathrm{a}}$ in $0.1 \mathrm{M}$ $\left(\mathrm{C}_{4} \mathrm{H}_{9}\right)_{4} \mathrm{NPF}_{6} / 2: 1$ toluene: $\mathrm{CH}_{3} \mathrm{CN}$.

metal-like core whose charging is controlled by electrostatic (i.e., double layer) principles. The evolution of molecule-like properties when the MPC core is very small is seen ${ }^{35 a}$ as a wide spacing between the two current peaks adjacent to the MPC potential-of-zero charge $\left(\mathrm{E}_{\mathrm{PZC}}\right.$, ca. $-0.2 \mathrm{~V}$ vs $\mathrm{Ag} / \mathrm{AgCl}$ ). This electrochemical band gap is consistent with the optical band gap of such MPCs.

It is important to understand that one-electron double layer charging peaks in MPC solutions are formally analogous to those produced by traditional redox reactions (i.e., oxidation of ferrocene). The double layer charging of MPCs is kinetically fast (demonstrably $35 a, c$ controlled by mass transport), so that the profile of working electrode current versus average potential of MPC cores in the adjacent solution is determined by traditional combinations of the Nernst equation with mass transport relationships. ${ }^{35 c}$ Each core charging step has a "formal potential", which, referenced to the MPC potential of zero charge $\left(z, E_{P Z C}\right)$, is ${ }^{35 c}$

$$
\mathrm{E}_{z, z-1}^{\circ}=\mathrm{E}_{\mathrm{PZC}}+\left(\mathrm{z}-1 /{ }_{2}\right) \mathrm{e} / \mathrm{C}_{\mathrm{CLU}}
$$

where $E_{z, z-1}^{\circ}$, the formal potential of the $z(z-1)$ chargestate "couple" corresponds to DPV peak currents (Figure 6b). $z$ is signed such that $z>0$ and $z<0$ correspond to core "oxidation" and "reduction", respectively. Insofar as $\mathrm{C}_{\mathrm{CLU}}$ is potential independent, which seems to be so for potentials not far removed from $\mathrm{E}_{\mathrm{PZC}}$, this relation predicts a linear plot of $E_{z, z-1}^{\circ}$ vs charge state, with $C_{C L U}$ determined from its slope. Recent studies ${ }^{35 d}$ of the monolayer chain length dependence of $\mathrm{C}_{\mathrm{CLU}}$ show that $\mathrm{C}_{\mathrm{CLU}}$ varies with the dielectric thickness in remarkable agreement with a simple concentric sphere capacitor model (Figure $6 c, d$ ). The simple model predicts no dependence in $\mathrm{C}_{\mathrm{CLU}}$ on solvent or electrolyte changes.

The charge stored on MPC cores can be used for chemical reactions. We have electrolytically stored charge on MPCs in solutions; ${ }^{36 a}$ these solutions can be dried and reconstituted with minimal loss of the MPC core charge upon redissolution. Charges can also be stored on MPCs using chemical reactions. ${ }^{36 b}$ Charged MPCs can be used as quantitative redox reagents; Figure 7 shows an example (without a drying step) of titration of an ethyl ferrocene solution with oxidatively charged MPCs. Charged MPCs also undergo electron transfer reactions with themselves, as shown by observing equilibrium potentials in solution mixtures of differently charged MPCs. All results to date
Scheme 3. Outline of Some Possible Areas of MPC Application

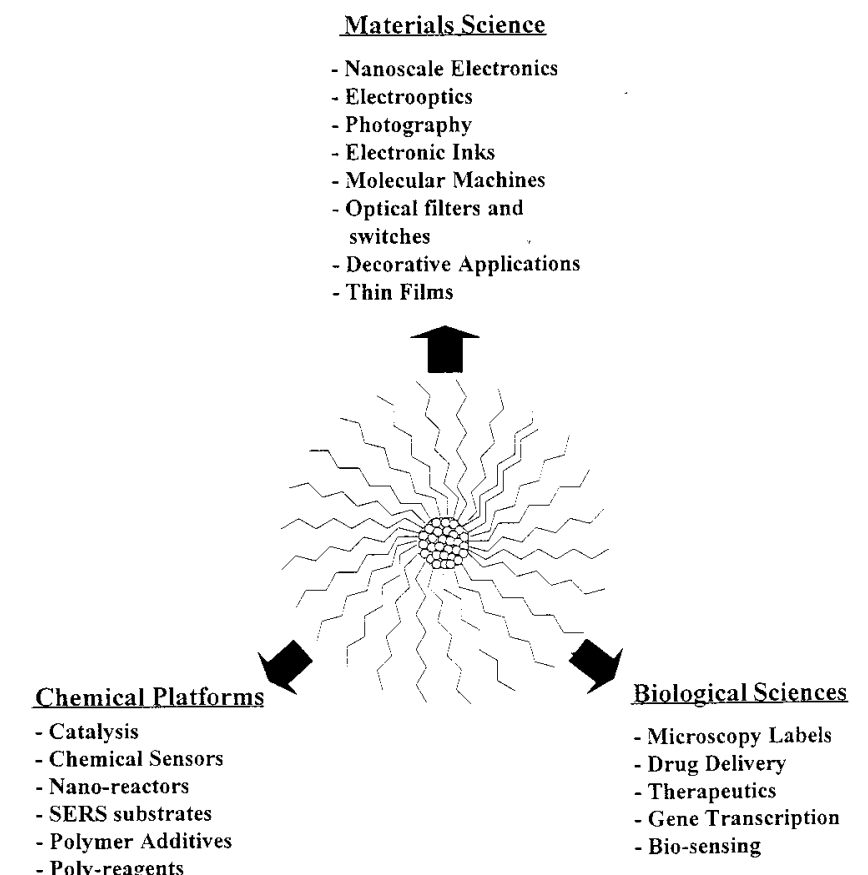

are consistent with the analogy of MPC core electrochemistry with regular redox reactions. Other analogies are of interest; optical ${ }^{37}$ and electron transfer dynamics properties of electronically charged MPCs are under active study.

Solid-State Electronic Conductivity. Dry (solid-state) films of alkanethiolate MPCs are electronically conductive, to degrees governed by core-to-core electron tunneling through intervening monolayers. Under high potential gradients, current-potential curves have been obtained $^{11}$ for dry MPC films that are characteristic of electron hopping conductivity. The electron hopping rates decreased and the activation barrier increased with increasing alkanethiolate chainlength, consistent with a combination of Cermet theory (hopping controlled by thermally activated electron transfer that creates oppositely charged Au cores) and chainlength-dependent tunneling. The MPCs gave a tunneling constant of $\beta=$ $1.2 / \AA$, similar to electron transfer rates studied ${ }^{38 a, b}$ in $2 \mathrm{D}$-SAMs of $\omega$-redox group functionalized alkanethiolates $(\beta \approx 1 / \AA)^{38 b}$ and confirmed by more recent work. ${ }^{38 c}$ MPCs with mixed core charge states exhibit enhanced electronic conductivity as expected for a "mixedvalent" material. ${ }^{38 d}$

\section{Conclusions and Outlook}

This report has described recent advances in the MPC field, but there remain numerous unexplored territories. Further understanding of MPC behavior requires expansion of synthetic routes to core-monodisperse MPCs and to those with rationally designed ligand shells and core compositions. Better understanding and control of these and other essential properties may lead to applications to areas such as outlined in Scheme 3. The substantial progress made in the five years since the Schiffrin route ${ }^{2 a}$ 
was published is impressive. Overall, however, we feel that this field is still in its infancy, and new fundamental insights and applications are almost certain to be revealed in the future.

We are indebted to present and past members of the Murray group, whose names are cited in the references, for their contributions to the work described in this Account. We also gratefully acknowledge our collaborators at UNC and at other institutions. This research has been supported by the NSF, DOE, and ONR, and at Oak Ridge National Laboratory under Contracts DE-ACO584OR21400, DE-AC05-760R00033, and DE-AC05-960R22464. A.C.T. acknowledges support from an ACS Division of Analytical Chemistry Graduate Research Fellowship, sponsored by Perkin-Elmer, while W.P.W. acknowledges support from a Lord Corporation Fellowship.

\section{References}

(1) (a) Schmid, G., Ed. Clusters and Colloids; VCH: Weinheim, 1994. (b) Hayat, M. A., Ed. Colloidal Gold: Principles, Methods, and Applications; Academic Press: New York, 1989; Vols. 1-2.

(2) Brust, M.; Walker, M.; Bethell, D.; Schiffrin, D. J .; Whyman, R. Synthesis of Thiol-derivatised Gold Nanoparticles in a Two-Phase Liquid-Liquid System. J. Chem. Soc., Chem. Commun. 1994, $801-802$.

(3) See, for example: (a) Pileni, M. P.; Tanori, J .; Filankembo, A.; Dedieu, J . C.; Gulik-Krzywicki, T. Template Design of Microreactors with Colloidal Assemblies: Control of the Growth of Copper Metal Rods. Langmuir 1998, 14, 7359-7363. (b) Cole, D. H.; Shull, K. R.; Baldo, P.; Rehn, L. Dynamic Properties of a Model Polymer/ Metal Nanocomposite: Gold Particles in Poly(tert-butyl acrylate) Macromolecules 1999, 32, 771-777. (c) Bell, R. C.; Zemski, K. A.; Castleman, A. W., J r. Gas-Phase Chemistry of Vanadium Oxide Cluster Anions: Reactions with $\mathrm{CCl}_{4}$. J . Phys. Chem. A 1999, 103, 1585-1591.

(4) (a) Schmid, G.; Morun, B.; Malm, J .-O. Pt $\mathrm{Pt}_{309} \mathrm{Phen}_{36} \mathrm{O}_{30 \pm 10}$, a FourShell Platinum Cluster. Angew. Chem., Int. Ed. Engl. 1989, 28, 778-780.

(5) Hostetler, M. J .; Wingate, J . E.; Zhong, C.-Z.; Harris, J . E.; Vachet, R. W.; Clark, M. R.; Londono, J. D.; Green, S. J .; Stokes, J . J .; Wignall, G. D.; Glish, G. L.; Porter, M. D.; Evans, N. D.; Murray, R. W. Alkanethiolate Gold Cluster Molecules with Core Diameters from 1.5 to $5.2 \mathrm{~nm}$ : Core and Monolayer Properties as a Function of Core Size. Langmuir 1998, 14, 17-30.

(6) (a) Fendler, J . H.; Meldrum, F. C. The Colloidal Chemical Approach to Nanostructured Materials. Adv. Mater. 1995, 7, 607-632. (b) Steigerwald, M. L.; Brus, L. E. Semiconductor Crystallites: A Class of Large Molecules. Acc. Chem. Res. 1990, 23, 183-188.

(7) See, for example: (a) Richardson, J . N.; Peck, S. R.; Curtin, L. S.; Tender, L. M. Terrill, R. H.; Carter, M. T.; Rowe, G. K.; Creager, S.; Murray, R. W. Electron-Transfer Kinetics of Self-Assembled Ferrocene Octanethiol Monolayers on Gold and Silver Electrodes from 115 to 170 K. J . Phys. Chem. 1995, 99, 766. (b) Hostetler, M. J .; Murray, R. W. Colloids and Self-Assembled Monolayers. Curr. Opin. Colloid Interface Sci. 1997, 2, 42-50.

(8) Ulman, A. Formation and Structure of Self-Assembled Monolayers. Chem. Rev. 1996, 96, 1533-1554 and references therein.

(9) Newkome, G. R.; Moorefield, C. N.; Vogtle, F. Dendritic MoleculesConcepts, Synthesis, Prospectives; VCH: New York, 1996 and references therein.

(10) Some reports describe monolayer-stabilized clusters prepared by capping an already-prepared colloid particle with an alkanethiol monolayer; such materials typically flocculate over time or with loss of solvent.

(11) Terrill, R. H.; Postlethwaite, T. A.; Chen, C.-H.; Poon, C.-D.; Terzis, A.; Chen, A.; Hutchison, J . E.; Clark, M. R.; Wignall, G.; Londono, J. D.; Superfine, R.; Falvo, M.; J ohnson, C. S., J r.; Samulski, E. T.; Murray, R. W. Monolayers in Three Dimensions: NMR, SAXS, Thermal, and Electron Hopping Studies of Alkanethiol Stabilized Gold Clusters. J . Am. Chem. Soc. 1995, 117, 12537-12547.

(12) J ohnson, S. R.; Evans, S. D.; Brydson, R. Influence of a Terminal Functionality on the Physical Properties of Surfactant-Stabilized Gold Nanoparticles. Langmuir 1998, 14, 6639-6647.

(13) Porter, L. A., J r.; J i, D.; Westcott, S. L.; Graupe, M.; Czernuszewicz, R. S.; Halas, N. J .; Lee, T. R. Gold and Silver Nanoparticles Functionalized by the Adsorption of Dialkyl Disulfides. Langmuir 1998, 14, 7378-7386.
(14) Leff, D. V.; O'Hara, P. C.; Heath, J . R.; Gelbart, W. M. Thermodynamic Control of Gold Nanocrystal Size: Experiment and Theory. J. Phys. Chem. 1995, 99, 7036-7041.

(15) (a) Whetten, R. L.; Khoury, J. T.; Alvarez, M. M.; Murthy, S.; Vezmar, I.; Wang, Z. L.; Stephen, P. W.; Cleveland, C. L.; Luedtke, W. D.; Landman, U. Nanocrystal Gold Molecules. Adv. Mater. 1996, 5, 428-433. (b) Schaaff, T. G.; Shafigullin, M. N.; Khoury, J . T.; Vezmar, I.; Whetten, R. L.; Cullen, W.; First, P. N.; GutierrezWing, C.; Ascensio, J .; J ose-Yacaman, M. J . Isolation of Smaller Nanocrystal Au Molecules: Robust Quantum Effects in Optical Spectra. J . Phys. Chem. B 1997, 101, 7885-7891. (c) Alvarez, M M.; Khoury, J. T.; Schaaff, T. G.; Shafigulin, M.; Vezmar, I.; Whetten, R. L. Critical Sizes in the Growth of Au Clusters. Chem. Phys. Lett. 1997, 266, 91-98.

(16) (a) Schaaff, T. G.; Knight, G.; Shafigullin, M. N.; Borkman, R. F.; Whetten, R. L. Isolation and Selected Properties of a $10.4 \mathrm{kDa}$ Gold:Glutathione Cluster Compound. J . Phys. Chem. B 1998, 102, 10643-10646. (b) Templeton, A. C.; Chen, S.; Gross, S. M.; Murray, R. W. Water-Soluble, Isolable Gold Clusters Protected by Tiopronin and Coenzyme A Monolayers. Langmuir 1999, 15, 6676. (c) Wuelfing, W. P.; Gross, S. M.; Miles, D. T.; Murray, R. W. Nanometer Gold Clusters Protected by Surface-Bound Monolayers of Thiolated Poly(ethylene glycol) Polymer Electrolyte. J . Am Chem. Soc. 1998, 120, 12696-12697. (d) Chen, S.; Kimura, K. Synthesis and Characterization of Carboxylate-Modified Gold Nanoparticle Powders Dispersible in Water. Langmuir 1999, 15 1075-1082. (e) Chen, S.; Murray, R. W. Arenethiolate MonolayerProtected Gold Clusters. Langmuir 1999, 15, 682-689. (f) J ohnson, S. R.; Evans, S. D.; Mahon, S. W.; UIman, A. Alkanethiol Molecules Containing an Aromatic Moiety Self-Assembled onto Gold Clusters. Langmuir 1997, 13, 51-57. (g) Brust, M.; Fink, J .; Bethell, D.; Schiffrin, D. J .; Kiely, C. Synthesis and Reactions of Functionalised Gold Nanoparticles. J. Chem. Soc., Chem. Commun. 1995, 1655-1656. (h) Buining, P. A.; Humbel, B. M.; Philipse, A. P.; Verkleij, A. J . Preparation of Functional Silane-Stabilized Gold Colloids in the (Sub)nanometer Size Range. Langmuir 1997, 13, 3921-3926.

(17) (a) Collier, C. P.; Saykally, R. J .; Shiang, J . J .; Henrichs, S. E.; Heath, J. R. Reversible Tuning of Silver Quantum Dot Monolayers Through the Metal-Insulator Transition. Science 1997, 277, 1978. (b) Hostetler, M. J .; Zhong, C.-J .; Yen, B. K. H.; Anderegg, J .; Gross, S. M.; Evans, N. D.; Porter, M.; Murray, R. W. Stable, Monolayer-Protected Metal Alloy Clusters. J . Am. Chem. Soc. 1998, 120, 9396-9397.

(18) See, for example: (a) Schiffrin, M.; Kiely, C. J .; Bethell, D.; Schiffrin, D. J . C 60 Mediated Aggregation of Gold Nanoparticles. J. Am. Chem. Soc. 1998, 120, 12367-12368. (b) Fink, J .; Kiely, C. J .; Bethell, D.; Schiffrin, D. J . Self-Organization of Nanosized Gold Particles. Chem. Mater. 1998, 10, 922-926.

(19) (a) Badia, A.; Singh, S.; Demers, L.; Cuccia, L.; Brown, G. B.; Lennox, R. B. Self-Assembled Monolayers on Gold Nanoparticles. Chem. Eur.J . 1996, 2, 359-363. (b) Badia, A.; Gao, W.; Singh, S.; Demers, L.; Cuccia, L.; Reven, L. Structure and Chain Dynamics of Alkanethiol-Capped Gold Colloids. Langmuir 1996, 12, $1262-$ 1269. (c) Badia, A.; Cuccia, L.; Demers, L.; Morin, F.; Lennox, R. B. Structure and Dynamics in Alkanethiolate Monolayers SelfAssembled on Gold Nanoparticles: A DSC, FT-IR, and Deuterium NMR Study. J . Am. Chem. Soc. 1997, 119, 2682-2692. (d) Badia, A.; Demers, L.; Dickinson, L.; Morin, F. G.; Lennox, R. B.; Reven, L. Gold-Sulfur Interactions in Alkylthiol Self-Assembled Monolayers Formed on Gold Nanoparticles Studied by Solid-State NMR. J. Am. Chem. Soc. 1997, 119, 11104-11105. (e) Hostetler M. J .; Stokes, J . J .; Murray, R. W. Infrared Spectroscopy of ThreeDimensional Self-Assembled Monolayers: $n$-Alkanethiolate Monolayers on Gold Cluster Compounds. Langmuir 1996, 12, 36043612.

(20) (a) Luedtke, W. D.; Landman, U. Structure, Dynamics, and Thermodynamics of Passivated Gold Nanocrystallites and their Assemblies. J. Phys. Chem. 1996, 100, 13323-13329. (b) Luedtke, W. D.; Landman, U. Structure and Thermodynamics of SelfAssembled Monolayers on Gold Nanocrystallites. J . Phys. Chem. B 1998, 102, 6566-6572.

(21) Templeton, A. C.; Hostetler, M. J .; Kraft, C. T.; Murray, R. W. Reactivity of Monolayer-Protected Gold Cluster Molecules: Steric Effects. J. Am. Chem. Soc. 1998, 120, 1906-1911

(22) (a) Hostetler, M. J ; Green, S. J .; Stokes, J . J .; Murray, R. W Monolayers in Three Dimensions: Synthesis and Electrochemistry of $\omega$-Functionalized Alkanethiolate-Stabilized Gold Cluster Compounds. J . Am. Chem. Soc. 1996, 118, 4212-4213. (b) Ingram R. S.; Hostetler, M.J .; Murray, R. W. Poly-hetero- $\omega$-functionalized Alkanethiolate-Stabilized Gold Cluster Compounds. J . Am. Chem. Soc. 1997, 119, 9175. (c) Hostetler, M. J .; Templeton, A. C.; Murray R. W. Dynamics of Place-Exchange Reactions on MonolayerProtected Gold Cluster Molecules. Langmuir 1999, 15, 3782-3789. 
(23) Templeton, A. C.; Hostetler, M. J .; Warmoth, E. K.; Chen, S.; Hartshorn, C. M.; Krishnamurthy, V. M.; Forbes, M. D. E.; Murray, R. W. Gateway Reactions to Diverse, Polyfunctional MonolayerProtected Gold Clusters. J . Am. Chem. Soc. 1998, 120, 4845-4849.

(24) Bethell, D.; Schiffrin, M.; Schiffrin, D. J .; Kiely, C. From Monolayers to Nanostructured Materials: An Organic Chemist's View of SelfAssembly. J . Electroanal. Chem. 1996, 409, 137-143.

(25) Frxyell, G. E.; Rieke, P. C.; Wood, L. L.; Engelhard, M. H.; Williford, R. E.; Graff, G. L.; Campbell, A. A.; Wiacek, R. J .; Lee, L.; Halverson, A. Nucleophilic Displacements in Mixed Self-Assembled Monolayers. Langmuir 1996, 12, 5064.

(26) Templeton, A. C.; Cliffel, D. E.; Murray, R. W. Redox and Fluorophore Functionalization of Water-Soluble, Tiopronin-Protected Gold Clusters. J. Am. Chem. Soc. 1999, 121, 7081-7089.

(27) See, for example: Veinot, J. G. C.; Ginzburg, M.; Pietro, W. J . Surface Functionalization of Cadmium Sulfide Quantum-Confined Nanoclusters: Formation and Derivatives of a Surface Phenolic Quantum Dot. Chem. Mater. 1997, 9, 2117-2122.

(28) Watson, K. J .; Zhu, J .; Nguyen, S. T.; Mirkin, C. A. Hybrid Nanoparticles with Block Copolymer Shell Structures. J. Am. Chem. Soc. 1999, 121, 462-463.

(29) (a) Flanagan, J . B.; Margel, S.; Bard, A. J .; Anson, F. C. Electron Transfer to and From Molecules Containing Multiple, Noninteracting Redox Centers. J. Am. Chem. Soc. 1978, 100, 4248. (b) Margerum, L. D.; Murray, R. W.; Meyer, T. J . Transient Storage of Photochemically Oxidative and Reductive Equivalents in Soluble Redox Polymers. J. Phys. Chem. 1986, 5, 728.

(30) (a) Green, S. J .; Stokes, J . J .; Hostetler, M. J .; Pietron, J . J .; Murray, R. W. Three-Dimensional Monolayers: Nanometer-sized Electrodes of Alkanthiolate-Stabilized Gold Cluster Molecules. J . Phys. Chem. B 1997, 101, 2663-2668. (b) Green, S. J .; Pietron, J . J .; Stokes, J . J .; Hostetler, M. J .; Vu, H.; Wuelfing, W. P.; Murray, R. W. Three-Dimensional Monolayers: Voltammetry of Alkanethiolate-Stabilized Gold Cluster Molecules. Langmuir 1998, 14, 5612-5619. (c) Lee, W.-J .; Hostetler, M. J .; Murray, R. W.; Majda, M. Electron Hopping and Electronic Conductivity in Monolayers of Alkanethiol-Stabilized Gold Nano-Clusters at the Air/Water Interface. Isr. J . Chem. 1997, 37, 213-223.

(31) (a) Ingram, R. S.; Murray, R. W. Electroactive Three-Dimensional Monolayers: Anthraquinone $\omega$-Functionalized AlkanethiolateStabilized Gold Clusters. Langmuir 1998, 14, 4115-4121. (b) Pietron, J.J.; Murray, R. W. Mediated Electrocatalysis with Polyanthraquinone-Functionalized Monolayer-Protected Clusters. J. Phys. Chem. B 1999, 103, 4440-4446.

(32) Wuelfing, W. P.; Templeton, A. C.; Hicks, J . F.; Murray, R. W. Taylor Dispersion Measurements of Monolayer-Protected Clus- ters: A Physiochemical Method of Nanoparticle Size Determination. Anal. Chem. 1999, 71, 4069-4074.

(33) Laibinis, P. E.; Whitesides, G. M.; Allara, D. L.; Tao, Y.-T.; Parikh, A. N.; Nuzzo, R. G. Comparison of the Structure and Wetting Properties of Self-Assembled Monolayers of n-Alkanethiols on the Coinage Metal Surfaces Cu, Ag, Au. J . Am. Chem. Soc. 1991, 113, 7152.

(34) (a) Logunov, S. L.; Ahmadi, T. S.; El-Sayed, M. A.; Khoury, J . T.; Whetten, R. L. Electron Dynamics of Passivated Gold Nanocrystals Probed by Subpicosecond Transient Absorption Spectroscopy. J. Phys. Chem. B 1997, 101, 3713-3719. (b) Alvarez, M. M. Khoury, J. T.; Schaaff, T. G.; Shafigullin, M. N.; Vezmar, I. Whetten, R. L. Optical Absorption Spectra of Nanocrystal Gold Molecules. J. Phys. Chem. B 1997, 101, 3706-3712.

(35) (a) Chen, S.; Ingram, R. S.; Hostetler, M. J .; Pietron, J . J .; Murray, R. W.; Schaaff, T. G.; Khoury, J . T.; Alvarez, M. M.; Whetten, R. L. Gold Nanoelectrodes of Varied Size: Transition to Molecule-Like Charging. Science 1998, 280, 2098-2101. (b) Ingram, R. S.; Hostetler, M. J .; Murray, R. W.; Schaaff, T. G.; Khoury, J . T. Whetten, R. L.; Bigioni, T. P.; Guthrie, D. K.; First, P. N. 28 kDa Alkanethiolate-Protected Au Clusters Give Analogous Solution Electrochemistry and STM Coulomb Staircases. J. Am. Chem. Soc. 1997, 119, 9279-9280. (c) Chen, S.; Murray, R. W.; Feldberg, S. W. Quantized Capacitance Charging of Monolayer-Protected Au Clusters. J . Phys. Chem. B 1998, 102, 9898-9907. (d) Hicks, J. F.; Templeton, A. C.; Chen, S.; Sheran, K. M.; J asti, R.; Murray, R. W.; Debord, J .; Schaaff, T. G.; Whetten, R. L. The Monolayer Thickness Dependence of Quantized Double Layer Capacitances of Monolayer-Protected Gold Clusters. Anal. Chem. 1999, 71, 3703-3711.

(36) (a) Pietron, J . J .; Hicks, J . F.; Murray, R. W. Using Electrons Stored on Quantized Capacitors in Electron-Transfer Reactions. J . Am. Chem. Soc. 1999, 121, 5565-5570. (b) Wuelfing, W. P.; Cliffel, D. E.; Murray, R. W., unpublished results.

(37) Templeton, A. C.; Pietron, J . J .; Murray, R. W.; Mulvaney, P. J Phys. Chem. B, submitted.

(38) (a) Sachs, S. B.; Dudek, S. P.; Hsung, R. P.; Sita, L. R.; Smalley, J F.; Newton, M. D.; Feldberg, S. W.; Chidsey, C. E. D. Rate of Interfacial Electron-Transfer Through $\pi$-Conjugated Spacers. J Am. Chem. Soc. 1997, 119, 10563-10564. (b) Smalley, J. F. Feldberg, S. W.; Chidsey, C. E. D.; Linford, M. R.; Newton, M. D.; Liu, Y.-P. The Kinetics of Electron Transfer through Ferroceneterminated Alkanethiol Monolayers on Gold. I. Phys. Chem. 1995 99, 13141. (c) Green, S. J .; Pietron, J . J .; Wuelfing, W. P.; Murray, R. W., manuscript in preparation, (d) Wuelfing, W. P.; Murray, R. W., manuscript in preparation.

AR9602664 